\title{
Rooting ability of Olive genotypes softwood cuttings under various rooting media
}

\author{
Muhammad Farhan Khan Pasha ${ }^{1 *}$, Summaira Ali ${ }^{2}$ and Abrar Ahmed ${ }^{3}$ \\ 1. Institute of Horticultural Sciences, University of Agriculture, Faisalabad-Pakistan \\ 2. Pir Maher Ali Shah-Arid Agriculture University Rawalpindi-Pakistan \\ 3. The University of Agriculture, Peshawar-Pakistan \\ *Corresponding author's email:farhan_khan9972@yahoo.com
}

Citation

Muhammad Farhan Khan Pasha, Summaira Ali and Abrar Ahmed. Rooting ability of Olive genotypes softwood cuttings under various rooting media. Pure and Applied Biology.Vol. 11, Issue 2, pp561-569.

\begin{tabular}{llll}
\hline \hline Received: 19/06/2021 & Revised: 12/08/2021 & Accepted: 27/08/2021 & Online First: 02/09/2021
\end{tabular}

\section{Abstract}

Olea europaea is the most imperative high quality oil-producing fruit tree in the Mediterranean region and propagated through cuttings. This tree has shown good rooting ability in European countries. However, in Pakistan, propagation of olive through softwood cuttings showed moderate or even poor rooting performance due to the utilization of inappropriate rooting media. The objective of the research work was to determine the rooting ability of olive cuttings under most suitable media. For this purpose, five different growing media were used against two olive Genotypes Coratina \& Frantoio at Agriculture Research Institute, Tarnab, Peshawar. Growing media consist of sand, silt, sawdust, perlite, and a mixture of (sand, silt \& garden soil respectively 1:1:1). The data of morphological parameters like days to rooting, number of sprouted cuttings, number of rooted cuttings, root length and successful plant percentage was recorded. It was explicable from noted data that sand media took minimum number of days $(115,118)$ for rooting in both cultivars Coratina \& Frantoio respectively. Maximum sprouted cuttings $(90,85)$ were observed in sand media for both the cultivars Coratina \& Frantoio respectively. Maximum rooted cuttings $(38,41)$ were noted for both cultivars Frantoio \& Coratina respectively again in sand media whereas maximum root length $(8.6 \mathrm{~cm}, 9.8 \mathrm{~cm}$, ) for both the genotypes Coratina \& Frantoio was recorded in compost. Considering media, Sand produced the best result regarding observed parameters overall whereas while considering genotype, Coratina as compare to Frantoio, performs better under subjected media in routing ability and other observed parameters.

Keywords: Cuttings; Genotype; Media; Rooting ability

\section{Introduction}

Olea europaea is evergreen and slowgrowing tree having more than 1000 years of age. It is among most vital members of the Oleaceae family and is cultivated for its edible oil and its fruits. The origin of $O$. europaea is Syria, Lebanon, and Palestine. Olives had never been conventionally grown for edible oil production in Pakistan even though a small number of wild grooves existed in plain and hills. The Oldest farming of olive recognized in Pakistan was in late 1970 [1]. It is amongst the oldest crops of the Southern European basin. O. europae is nearly all iconic species owing to its economical, ecological and cultural 
importance [2]. In fact the utilization of table olives as well as olive oil has been revealed to be connected with a diversity of physical condition and benefits, comprising a lesser frequency of heart ailment and firm types of cancer $[3,4]$.

It is propagated by both sexual and asexual methods. It is generally recommended to multiply olives by a-sexual means through cutting or air-layering because seedlings are genetically true to type. It could take more time to bear fruit if adopt sexual means of propagation. The most common and commercial method for propagation is asexual or vegetative propagation strategies. Budding, grafting, and air-layering are techniques used for asexual propagation [5]. In milder climates, the Frantoio tree grows well, but is not as tolerant of heat and cold as the Spanish olive cultivars. The tree expands slightly and is shaped into an airy canopy. In the favorable conditions, it appears to be highly active and has a tendency to flourish more like a tree than a forest, which is distinct from other olive trees. The average oil yield is $23-28$ percent of the fruit. Frantoio is selfpollinated and is excellent for other cultivars as pollinator. Notice that it would improve yield through cross-pollination. The Coratina is one of the most essential Italian varieties, especially the largest olive growing region in Italy in the area of Puglia, and is also available in Argentina, Australia, and Northern California. In addition, agroclimate environments have a great effect on numerous morphological parameters. Important differences were found in the morphological and yield-related characteristics of each Zinnia cultivar [6].

$O$. europaea could be multiplied in many forms, while mist propagation is probably the most commonly used process for leafy cuttings [7]. Unfortunately, in most olive producing countries, economically significant cultivars that display intermediate or even weak rooting ability are found.
Colonial variety, cutting material type, hormone concentration (indole butyric acid) added, and the rooting medium's physical properties may all affect rooting, particularly in more difficult-to-root cultivars [8-10].

In the propagation system, rooting media must be taken into account as an essential part [11]. The subjected medium directly influences the successful rooting percentage and reliability of generated roots. The adequacy of the medium depends on the species, the method of cutting, the season, the propagation device used, as well as the cost and availability of the medium components and effective water control [7, 12].

Despite its obvious drawbacks, for economic reasons, coarse sand has become more common in Turkey lately. 'Ayvalik', also referred to as 'Ada Zeytini', 'EdremitYağlık', 'Midilli' or ' akran' is the main cultivar produced in Turkey for high-quality olive oil [13]. The rooting of Ayvalik cuttings is typically moderate or often bad, considering its recent classification as a cultivar that shows strong rooting capacity. The rooting media used could be a result of bad rooting. $[14,15]$. The aim of the present research study was to evaluate rooting ability of olive genotype and the most thriving substrate those which are traditionally used in olive plant multiplication by means of cutting under agro climatic conditions of Peshawar, Pakistan.

\section{Materials and Methods}

Preparation of semi-hard wood cuttings of olive genotypes were taken from one-yearold uniform branches in the month of February 2018. The lengths of cuttings were 5 to 6 inches approximately, having 3 to 4 buds. Misting system was used for irrigation of cuttings. Experiment was conducted at Agriculture Research Institute, Tarnab in Peshawar Pakistan. It is situated at latitude and longitude coordinates of 34.025917 , 71.560135 respectively. During the year, 2018 average temperature, precipitation, and 
humidity data for the month of February to April was recorded and given in the (Table $1)$.

Table 1. Weather conditions

\begin{tabular}{|c|c|c|c|c|c|}
\hline \multirow{2}{*}{ Month } & \multicolumn{3}{|c|}{ Temperature $^{*}$ Humidity \% } & \multirow{2}{*}{ Precipitation mm } \\
\cline { 2 - 4 } & Maxi $^{\circ} \mathbf{C}$ & Mini $^{\circ} \mathbf{C}$ & $\mathbf{A v}^{\circ} \mathbf{C}$ & & 78 \\
\hline February & 19 & 8 & 14 & 64 & 69.8 \\
\hline March & 25 & 13 & 19 & 61 & 69 \\
\hline April & 30 & 17 & 24 & 55 & \\
\hline
\end{tabular}

To initiate rooting in olive, cuttings were treated with IBA @3000 ppm and then placed to unlike media of sand, silt, compost, Perlite, and Mix media (1:1:1) in polythene bags. In the experiment, there were three replications. The trial was laid out in a RCBD (randomized complete block design) with two genotypes and five Medias in each plot. All cultural agronomic operations were kept homogeneous for all necessary treatments throughout trial.

The information of data was recorded against bellow mention morphological parameters:

\section{Days to rooting}

The number of days to root appearance and averages was calculated after the date of cutting and media treatments recorded in each treatment.

\section{Sprouted cutting}

Numbers of sprouted cuttings were noted and data was recorded in each treatment.

\section{Rooted cuttings}

Numbers of rooted cuttings were counted, and data were recorded in each treatment.

\section{Root length (cm)}

Root length was calculated from bottom to the tips of roots. The averages were measured after recording the roots length calculation in each replication.

\section{Successful plants (\%)}

At end of the trial, plants were counted. The percentage formula calculated survival plant $\%$ ages.

\section{Statistical analysis}

Recorded data were statistically examined by using the technique "analysis of variance". Comparison of means was interpreted according to LSD test at $5 \%$ level of significance [16]. Olive cuttings were obtained from olive germ plasm unit (GPU) Agriculture Research Institute Peshawar. The experiment material comprises of two olive varieties and five different medias.

\section{Results and Discussion}

The initiation and development of roots in olive cuttings can be achieved by using various cultivars and media that are required by plants and have a major impact on the sprouting and rooting of cuttings. To attain this objective, two cultivars were propagated through cutting and some important traits were studied to conclude the performance of olive cultivars under different media. The mean value of two genotypes under five different media was calculated for studying the desired parameters given in (Table 2). Analysis of variance revealed that there were highly significant differences among the olive cultivars for a different type of media.

\section{Numbers of sprouted cuttings}

The mean values of the data presented in (Fig. 1) exhibit that there was a significant difference in the numbers of sprouted cuttings regarding media, however the mean value showed no significant difference among the genotypes. Data regarding media demonstrates that more sprouted cuttings were observed in sand (90.00), which is 
significantly different from silt, perlite, compost, and mixture.

The main reason involved in efficient performance of sand was the aeration, nutrient enrichment and good drainage of the medium which caused quick sprouting. It was also found that large most tangential roots were achieved in the media with good aeration and drainage [12]. In a related study [15] examined the performance of Ayvalik olive cuttings in volcanic scoria, but there was no significant differences in rooting during two years of their research work was identified. Furthermore, the rooted cutting numbers ranged from $41 \%$ to $56 \%$.

Table 2. Mean table of morphological parameters

\begin{tabular}{|c|c|c|c|c|c|c|}
\hline Coratina & $\begin{array}{c}\text { No. of Sprouted } \\
\text { cutting }\end{array}$ & $\begin{array}{c}\text { Days to } \\
\text { sprout }\end{array}$ & $\begin{array}{c}\text { Days to } \\
\text { Rooting }\end{array}$ & $\begin{array}{c}\text { No. Rooted } \\
\text { cuttings }\end{array}$ & $\begin{array}{c}\text { Root length } \\
\text { (cm) }\end{array}$ & $\begin{array}{c}\text { Successful } \\
\text { Plants (\%) }\end{array}$ \\
\hline Sand & 92 & 59 & 110 & 41 & 9.3 & 23 \\
\hline Silt & 84 & 63 & 120 & 30 & 5.06 & 32 \\
\hline Compost & 73 & 66 & 115 & 27 & 9.93 & 19 \\
\hline Perlite & 74 & 60 & 118 & 23 & 8.8 & 20 \\
\hline Mixture(1:1:1) & 70 & 69 & 130 & 20 & 8.92 & 16 \\
\hline Frantoio & \multicolumn{5}{|l|}{} & \\
\hline Sand & 88 & 56 & 98 & 39 & 10 & 22 \\
\hline Silt & 84 & 64 & 116 & 29 & 6.77 & 30 \\
\hline Compost & 78 & 68 & 112 & 30 & 8.53 & 18 \\
\hline Perlite & 71 & 58 & 119 & 22 & 10 & 19 \\
\hline Mixture(1:1:1) & 69 & 73 & 128 & 19 & 9.33 & 17 \\
\hline
\end{tabular}

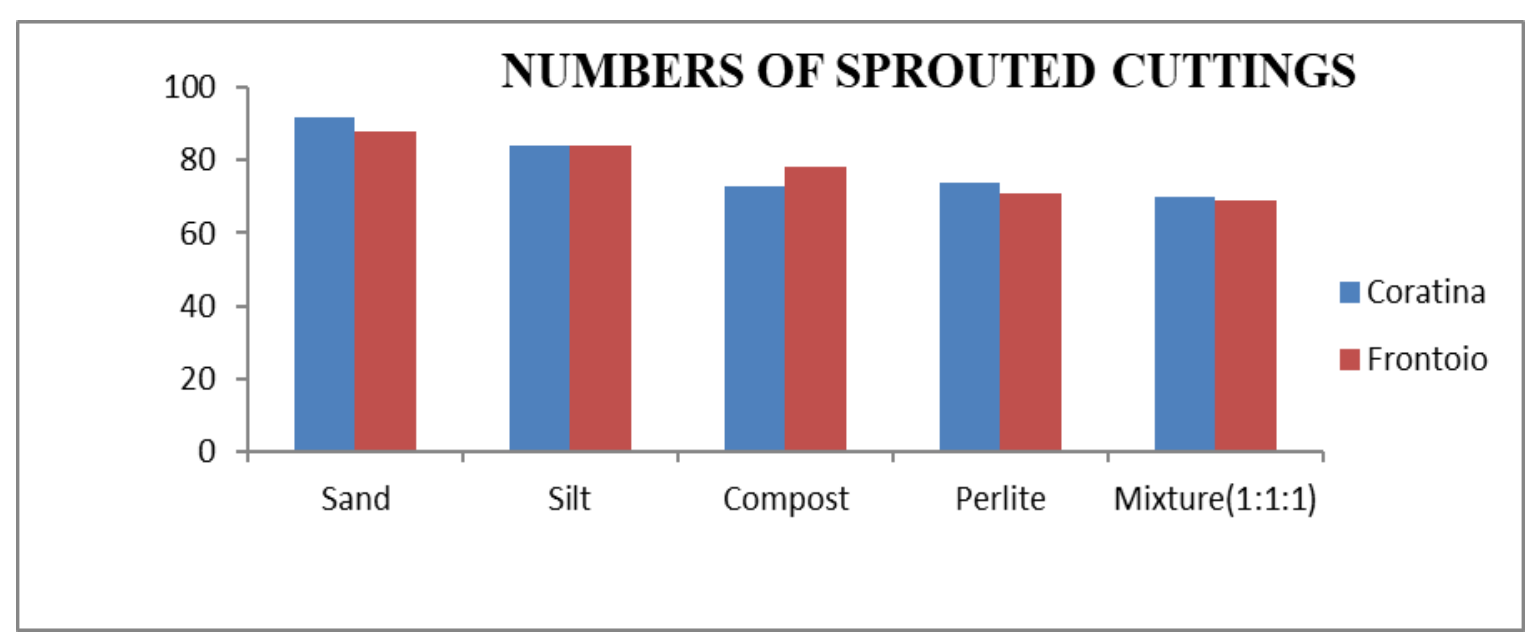

\section{Figure 1. Number of sprouted cuttings}

\section{Days to sprouting}

The mean values of the data presented in (Fig. 2) interpret that there was a significant difference in days to sprout cuttings regarding media, however the mean value showed no significant difference among the genotypes. Data regarding media reveal that minimum days to sprout cuttings were observed in sand (56.00) which is significantly different from silt, compost and 
mixture but no significant difference was observed to Perlite.

Media of rooting should be considered an essential part of the propagation system [11]. The percentage of rooting and the consistency of the generated roots are directly affected by the medium. It was revealed that the quickest sprouting occurred in cuttings that were planted in sawdust [17]. In sand-perlite bed and in peat-perlite bed treating with IBA had a fast time of callus induction and root induction observed by [18].

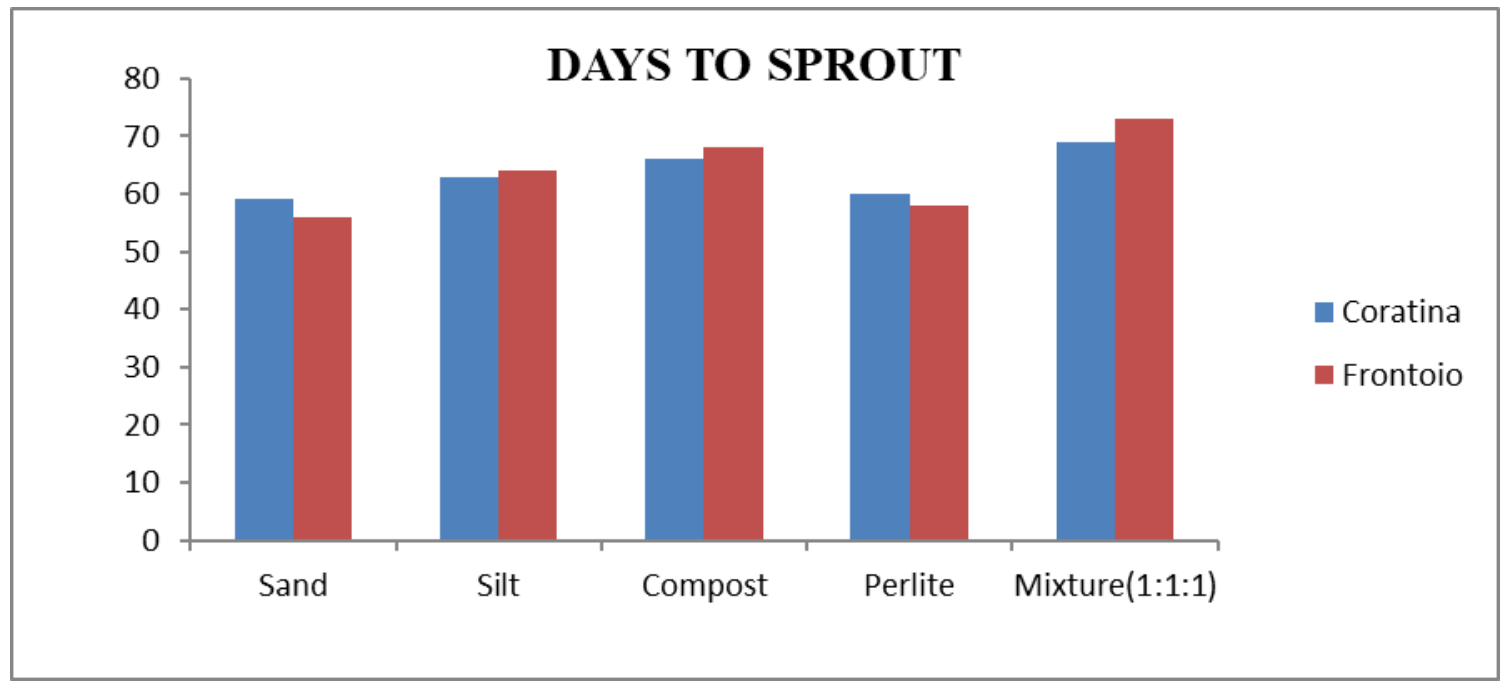

Figure 2. Days to sprout

\section{Days to rooting}

The mean values presented in (Fig. 3) exhibit significant difference in days to rooting regarding both genotype and media. Frantoio took more days (118) to rooting than Coratina. Similarly, the mean values showed significant difference among the media. Data demonstrates that more days to rooting were observed in mixture media (129) significantly different from sand, perlite, compost, and silt.

Coratina took less number of days to root which could be referred to its genotypic ability for regeneration in a conducive environment. So the results were in line with the finding of [19] who reported that rooting results of Coratina showed its quick ability to rooting than Baincullela. It seems that sand had more air spaces, good drainage and nutrients as compared to the other media of the experiment that's why sand media showed better results for rooting. Similar findings were evident by [20] who found that sand generates more root percentage out of three rooting media and requires a minimum amount of days to root in the experiment.

\section{Number of rooted cuttings}

Mean values of the datapresented in (Fig. 4)reveala significant difference in the number of rooted cuttings when comparing media. However, there was observed less significance difference among the genotype. Data indicates that sand media produced more number of rooted cuttings (40.88) which was significantly more than silt, perlite, compost, and mixture media.

Our research outcomes are confirmed by the results of previous research by [20] who evaluated that, on trial bases results, it was found in three rooting substrates, in which sand substrates provide the best result in terms of rooting percentage. It is also obvious that higher rooting percentages were obtained in media with sand and perlite used for 
improved drainage of the soil [17]. Other than its obvious drawbacks, for economic reasons, coarse sand has become more common in Turkey lately. 'Ayvalik', often referred to as 'Ada Zeytini', 'EdremitYağlık', 'Midilli' or ' akran' [13].

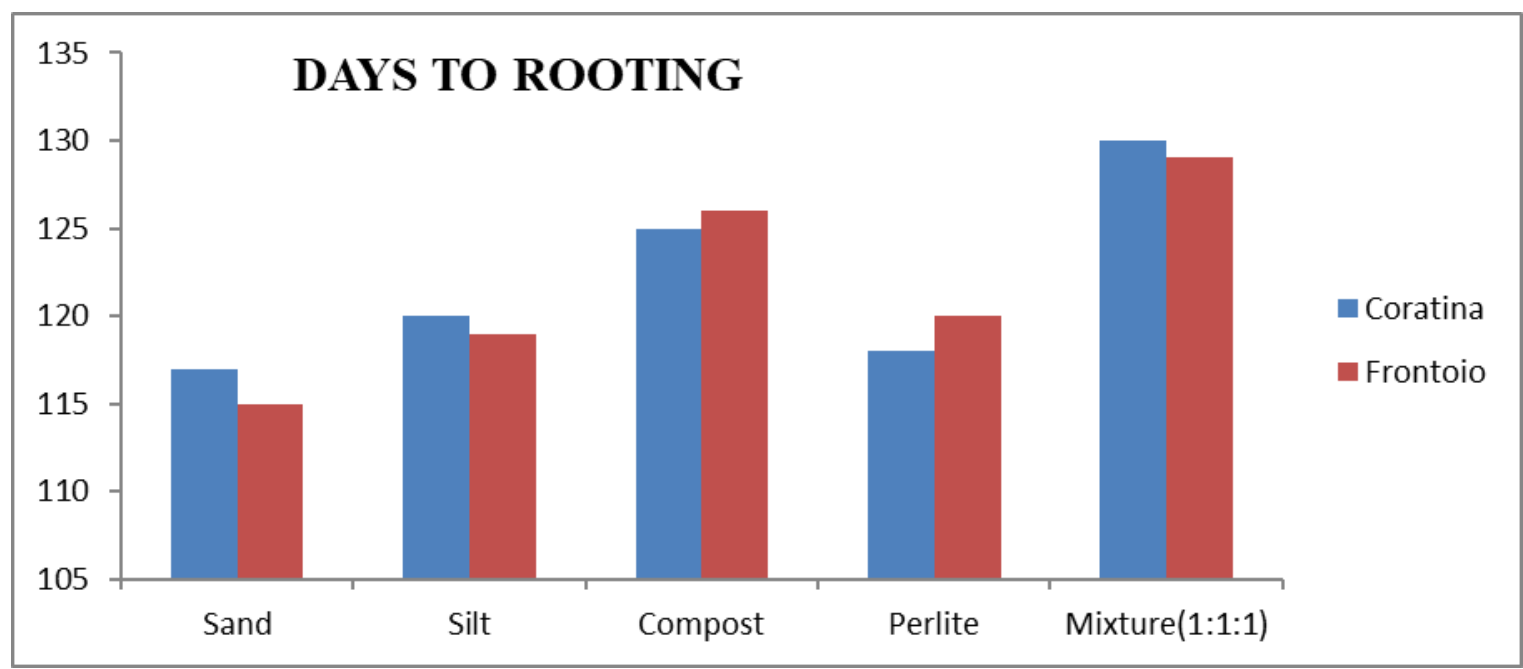

Figure 3. Days to rooting

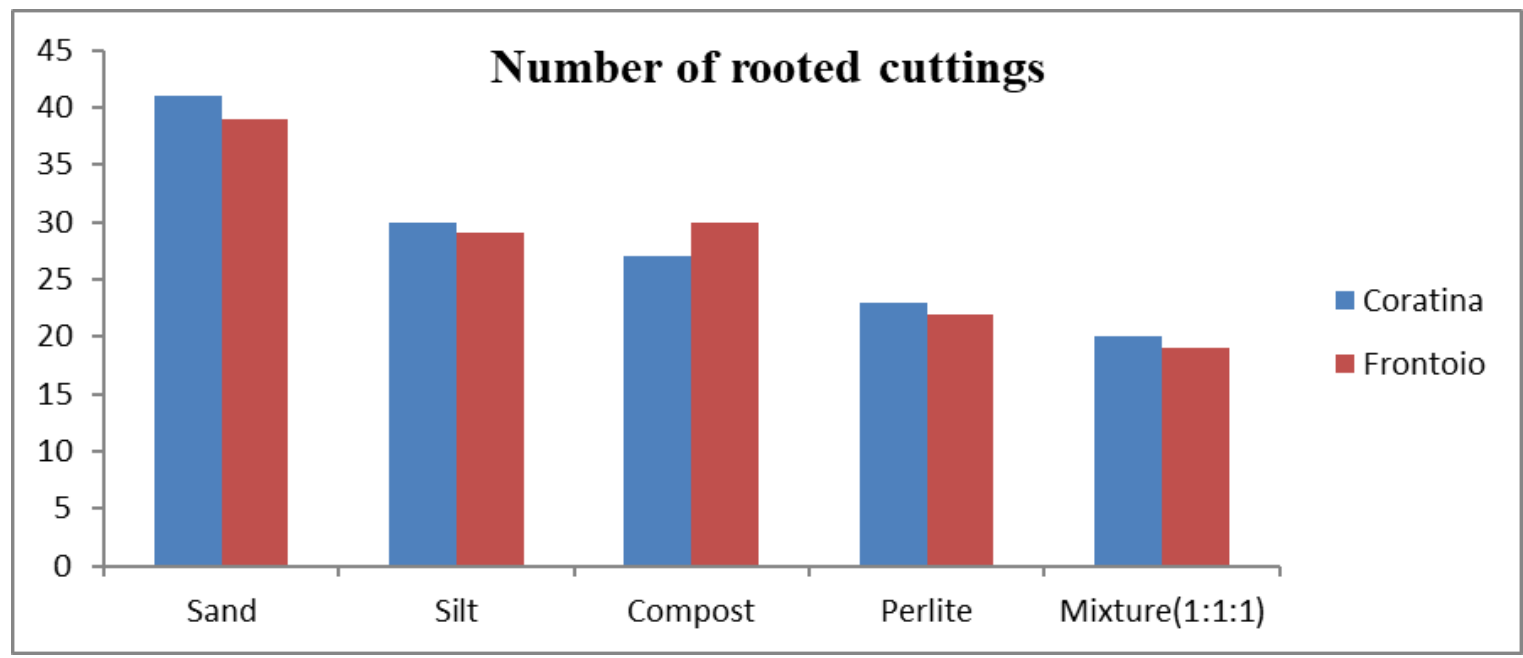

Figure 4. Number of rooted cuttings

\section{Root length $(\mathbf{c m})$}

Mean values of the data presented in (Fig. 5) reveal a significant difference in the number of rooted cuttings when comparing media. However, there was observed no significance difference among the genotype. Data indicates that sand media produced more number of rooted cuttings (40.88) which was significantly more than silt, perlite, compost, and mixture media.
The downward moment of water and nutrients was the key explanation for the best sand results since the roots had to consume the water and nutrients from deep there for their duration to improve [22]. Similar findings are observed in Carnation's sand. Rooting and root duration indicated may be increased by the usage of perlite and sand substrate [19]. 


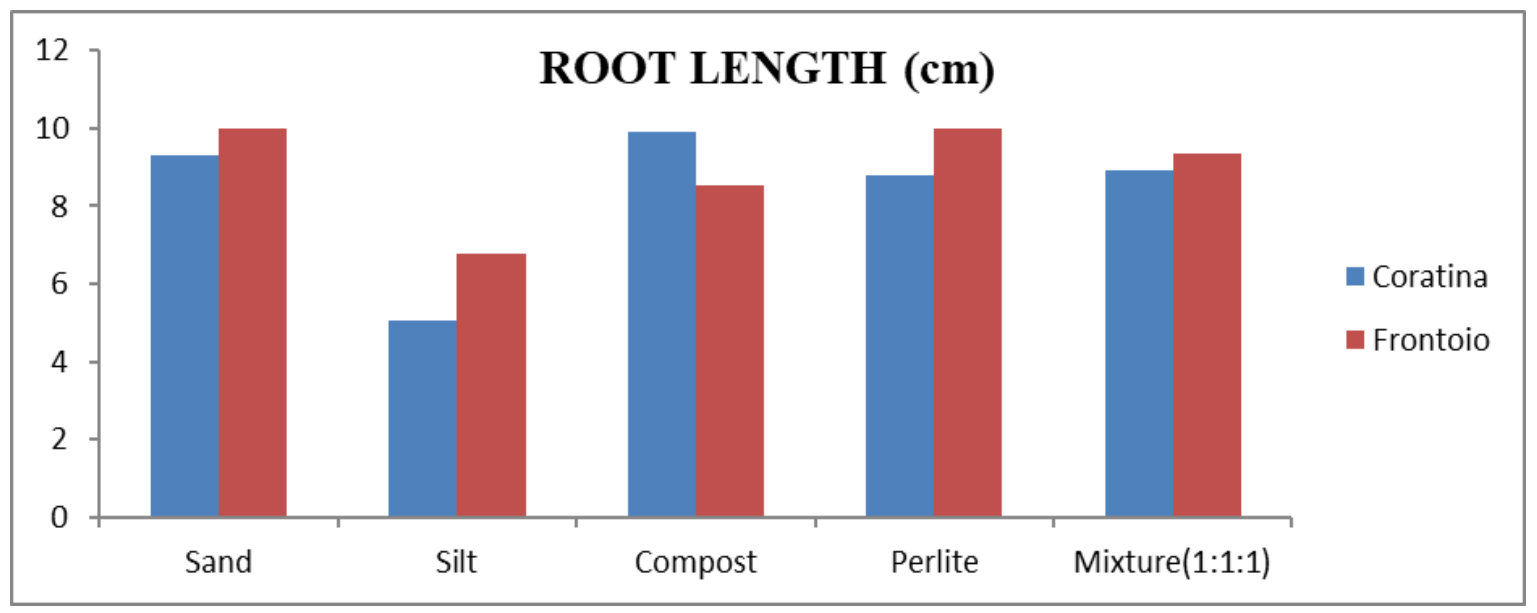

Figure 5. Root Length $(\mathrm{cm})$

\section{Percentage of successful plant}

Means of the data presented in (Fig. 6) shows a significant deviation in the successful cuttings quantity regarding media; however, there was observed no significance difference among the genotype. Data exhibits that silt media produced more number of successful cuttings $(30.333 \%)$ which was significantly more than sand, perlite, compost, and mixture media. There did not exist significant difference between sand to perlite and compost to mixture media.
Maximum number of plant survival in silt could be due to its water holding capacity, fertility and pore spaces. Silt media culminated in greater root length and root diameter, resulting in elevated plant survival [23]. Our results are also in lined with findings of research resulted maximum plant survival was observed by layering in silt followed by sand, while minimum plant survival was reported in FYM [19].

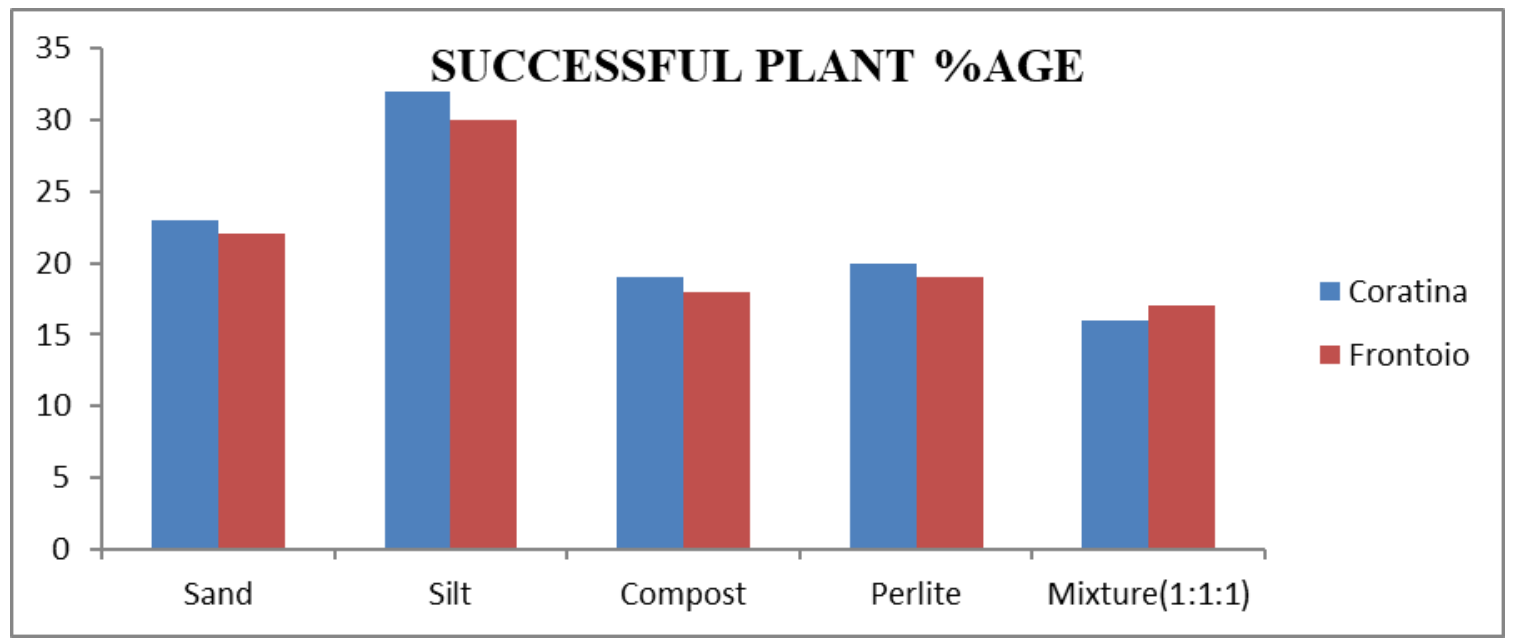

Figure 6. Successful plant \%age 


\section{Conclusion}

Results of morphological parameter were studied by mean of approperiate statistical analysis. The resultsillustrated that signifcant deviation was observed under the given agroclimatic conditions of Peshawar among rooting ability of the media.The success in rooting was also significantly influenced by genotype as well. While considering genotypes only Corotina cuttings showed good response as compare to cuttings of Frantoio in rotting ability and other parameters. whereas when considering media only maximum number of rooted cutting were obtained in sand media among all other media.

\section{Authors' contributions}

Conceived and designed the experiment: MFK Pasha, Performed experiment: MFK Pasha, Analyzed Data. MFK Pasha \& A Ahmed, Contribute to material and analysis tools: MFK Pasha \& S Ali, Wrote paper: MFK Pasha.

\section{Acknowledgements}

The authors would like to thank all the learned colleagues of the affiliated institutions for their selfless expert input and technical facilitation.

\section{References}

1. Wilson P (1920). Manual of tropical and subtropical fruits. MacMillan publishing Co., Inc. New York. pp. 321-323.

2. Zohary D, Hopf M \& Weiss E (2012). Domestication of plants in the Old World: The origin and spread of cultivated plants in Southwest Asia, Europe, and the Mediterranean basin. Oxford, UK: Oxford University Press.

3. Tuck KL \& Hayball PJ (2002). Major phenolic compounds in olive oil: metabolism and health effects. $J$ Nutr Biochem 13: 636-644.

4. Aruoma OI (2003). Methodological considerations for characterizing potential antioxidant actions of bioactive components in plant foods. Mutation
Research-Fundamental and Molecular Mechanisms of Mutagenesis. 523: 9-20.

5. Kanwar JS \&Kahlon GS (1986). Propagation studies in litchi. $J$ Res Punjab Agric Uni 23(1): 33-39.

6. Pasha MFK, Ahmad HM, Qasim M \& Javed I (2015). Performance evaluation of zinnia cultivars for morphological traits under the Agro-climatic conditions of Faisalabad. Eur J Biotech Biosci 3(1): 35-38.

7. Hartmann HT, Kester DE, Davies FT \&Geneve RL (2002). Plant propagation principles and practices.7th ed., Prentice Hall, NJ. pp. 880.

8. Loreti F \& Hartmann HT (1964). Propagation of olive trees by rooting leafy cuttings under mist. Proc Am Soc Hort Sci 85: 257-264.

9. Fernandes Serrano JM, Serrano M \&Amaral E (2002). Effect of different hormone treatments on rooting of Oleaeuropaea cv. Galega vulgar cuttings. Acta Horticul 586: 875-877.

10. Gerrakakis AC \& Özkaya MT (2005). Effects of cutting size, rooting media and planting time on rooting of Domat \& Ayvalik olive (Oleaeuropaea L.) cultivars in shaded polyethylene tunnel (spt.). Tarim Bilimleri Dergisi 11(3): 334-338.

11. Loach K (1988). Controlling environmental conditions to improve adventitious rooting. Dioscorides Press, Portland, Oregon, pp. 248- 279.

12. Macdonald B (1986). Practical woody plant propagation for nursery growers. Vol. I, fourth printing, Timber Press, Portland, Oregon. pp. 669.

13. Barranco D, Cimato A, Fiorino P, Rallo L, Touzani A, Castañeda C, Serafini F \&Truji-Llo N (2000). World catalogue of olive varieties. International Olive Oil Council, Madrid. pp. 360.

14. Battaglini M, Humanes J \&Preziosi P (1975). Observacionessobre la 
capacidadrizógena de 34 cultivares de Oleaeuropea L. sometidas a tratamiento con acido $\beta$-indolbutírico (AIB) eninvernaderocontrolado. Olea, Junio 11-25.

15. Luma Y, Atalay E \& Özvardar O (1991). Researches on determination of seasonal changes in softwood cuttings of some olive cultivars rooted with mist-spraying method. Proc. 1st Symposium of Nursery Production of Turkey, Rooting of olive cuttings 171 Turkish Ministry of Agriculture and Rural Affairs, Ankara. pp. 211-221.

16. Steel RCD \& Torries JH (1980). Principle and procedure of statistics. McGraw Hill Book. Co, Inc. Newyark. pp. 336-354.

17. Shah M, Khattak AM \& Amin N (2006). Effect of different growing media On the Rooting of Ficus Binnendijkii 'Amstel Queen' Cuttings. ARPN 1(3): 15-17.

18. Shadparvar V, Torkashvand MA \& Alamshiri AH (2011). Eur J of Exp Biol 1(4):142-146.
19. Awan AA, Iqbal A, Rehman J\& Idris G (2002). Response of olive hard wood cutting to different growth media and basal injuries for propagation. Asian $J$ Plant Sci 2(12): 883-886.

20. Hechmi M, AbidMKS, EL-Hassen A, Faiez R \& Hamid AM (2013). Performance of olive cuttings (Oleaeuropaea L.) of different cultivars growing in the agro-climatic conditions of Al-Jouf (Saudi Arabia). Ajpp10-3923.

21. Mighani H, SoleimaniA \& Askari N (2010). 6th Iranian congress of horticulture. 22-25 May, University of Guilan., pp. 952-954.

22. Lal, SD \& Dana NS (1985). Rooting of carnation cuttings as influenced by different rooting media. Prog Hort 17(2): 145-147.

23. Mathad MC \& Nalwadi UG (1989). Rooting ability of some important ornamental climbers. South Indian Hort 37(5): 307-308. 